\title{
Pathophysiological role of leptin in obesity-related hypertension
}

\author{
Megumi Aizawa-Abe, Yoshihiro Ogawa, Hiroaki Masuzaki, Ken Ebihara, Noriko Satoh, \\ Hidenori Iwai, Naoki Matsuoka, Tatsuya Hayashi, Kiminori Hosoda, Gen Inoue, \\ Yasunao Yoshimasa, and Kazuwa Nakao
}

Department of Medicine and Clinical Science, Kyoto University Graduate School of Medicine, Sakyo-ku, Kyoto, Japan

Address correspondence to: Yoshihiro Ogawa, Department of Medicine and Clinical Science,

Kyoto University Graduate School of Medicine, 54 Shogoin Kawahara-cho, Sakyo-ku, Kyoto 606-8507, Japan.

Phone: 81-75-751-3173; Fax: 81-75-771-9452; E-mail: ogawa@kuhp.kyoto-u.ac.jp.

Received for publication September 3, 1999, and accepted in revised form March 8, 2000.

To explore the pathophysiological role of leptin in obesity-related hypertension, we examined cardiovascular phenotypes of transgenic skinny mice whose elevated plasma leptin concentrations are comparable to those seen in obese subjects. We also studied genetically obese KKA $A^{y}$ mice with hyperleptinemia, in which hypothalamic melanocortin system is antagonized by ectopic expression of the agouti protein. Systolic blood pressure (BP) and urinary catecholamine excretion are elevated in transgenic skinny mice relative to nontransgenic littermates. The BP elevation in transgenic skinny mice is abolished by $\alpha_{1}$-adrenergic, $\beta$-adrenergic, or ganglionic blockers at doses that do not affect BP in nontransgenic littermates. Central administration of an $\alpha$-melanocyte-stimulating hormone antagonist causes a marked increase in cumulative food intake but no significant changes in BP. The obese KKA mice develop BP elevation with increased urinary catecholamine excretion relative to control KK mice. After a 2-week caloric restriction, BP elevation is reversed in nontransgenic littermates with the $A^{y}$ allele, in parallel with a reduction in plasma leptin concentrations, but is sustained in transgenic mice overexpressing leptin with the $A^{y}$ allele, which remain hyperleptinemic. This study demonstrates BP elevation in transgenic skinny mice and obese $\mathrm{KKA}^{y}$ mice that are both hyperleptinemic, thereby suggesting the pathophysiological role of leptin in some forms of obesity-related hypertension.

J. Clin. Invest. 105:1243-1252 (2000).

\section{Introduction}

Obesity is defined as increased mass of adipose tissue and confers a higher risk of arterial blood pressure (BP) elevation or hypertension (1-4). On the other hand, weight reduction lowers $\mathrm{BP}$ in obese hypertensive subjects (5-8), suggesting an important association between energy homeostasis and BP. However, the mechanism for that association is poorly understood. Obesity-related hypertension may be secondary to insulin resistance and/or hyperinsulinemia $(2,3,8)$. Several lines of evidence have also suggested that increased sympathetic nerve activity may contribute to the development of obesity-related hypertension $(2,6,7)$.

The adipose tissue participates in the regulation of a variety of homeostatic processes as an endocrine organ that secretes many biologically active molecules such as FFA, adipsin, angiotensinogen, and TNF- $\alpha(9)$. Leptin is such an adipocyte-derived hormone that is involved in the regulation of food intake and body weight (10). It also increases the overall sympathetic nerve activity, which leads to a significant increase in energy expenditure (11-15). The biologic actions of leptin are thought to be mediated through the activation of leptin receptor that is expressed in the hypothalamus (16-19). We and others demonstrated that the hypothalamic arcuate nucleus is a primary site of the satiety effect of leptin (20,
21) and that its satiety effect is mediated at least partly by hypothalamic melanocortin system $(22,23)$.

Numerous studies have demonstrated that plasma leptin concentrations are elevated significantly in several models of rodent obesity and in human obesity in proportion to the degree of adiposity (24-26), suggesting the state of "leptin resistance" in obesity. Nevertheless, because of the potent pleiotropic actions of leptin, it is conceivable, though paradoxically, that hyperleptinemia may be involved in the pathogenesis of obesity and its related disorders. In this regard, a recent study reported a significant correlation between BP and plasma leptin concentrations in patients with essential hypertension (27), suggesting that leptin may play roles in the pathogenesis of obesity-related hypertension.

We have recently produced transgenic skinny mice overexpressing leptin under the control of the liver-specific promoter and demonstrated that chronic hyperleptinemia results in complete disappearance of adipose tissue for a long period (28). These mice also exhibit increased glucose metabolism and insulin sensitivity, accompanied by an activation of insulin signaling in the skeletal muscle and liver $(28,29)$. Accordingly, transgenic skinny mice will serve as the unique experimental model system with which to assess the long-term effects of leptin in vivo. 
In this study, to explore the pathophysiological role of leptin in obesity-related hypertension, we examined the cardiovascular phenotypes of transgenic skinny mice overexpressing leptin. We also studied genetically obese $\mathrm{KK} A^{y}$ mice with hyperleptinemia, which develop a maturity-onset obesity and diabetes syndrome and resistance to the satiety effect of leptin (30-32) as a consequence of the antagonism of hypothalamic melanocortin system by ectopic expression of the agouti protein $(33,34)$.

\section{Methods}

Animals. Generation of transgenic skinny mice overexpressing leptin under the control of the human serum amyloid $\mathrm{P}$ component (SAP) promoter on the C57BL/6J background was reported elsewhere (28). Male transgenic skinny mice carrying 30 copies of the transgene were used in this study. Ten-week-old male leptin-deficient C57BL/6J ob/ob mice and their control C57BL/6J mice (10), and male $\mathrm{KK}^{y}$ mice and their control KK mice $(35,36)$, were purchased from Japan CLEA (Tokyo, Japan). We also crossed transgenic skinny mice with $\mathrm{KK} A^{y}$ mice to obtain F1 animals with different genotypes on the C57BL/6J and KK hybrid background (29); they were nontransgenic mice without the $A^{y}$ allele $(+/+$ mice $)$, transgenic mice without the $A^{y}$ allele $(\mathrm{Tg} /+$ mice $)$, nontransgenic mice with the $A^{y}$ allele $\left(A^{y} /+\right.$ mice $)$, and transgenic mice with the $A^{y}$ allele
$\left(\mathrm{Tg} /+: A^{y} /+\right.$ mice $)$. Animals were maintained in standard rat chow (CE-2, $352 \mathrm{kcal} / 100 \mathrm{~g}$; Japan CLEA) on a 12hour light/dark cycle. All experimental procedures were approved by the Kyoto University Graduate School of Medicine Committee on Animal Research.

Systolic BP and heart rate measurements. Systolic BP and heart rate were measured in 12-week-old transgenic skinny mice and ob/ob mice, and KKA $A^{y}$ mice and their age-matched control mice, by the tail-cuff method (PS200; Riken-Kaihatsu, Tokyo, Japan) (37). At least 6 recordings were taken for each measurement. The systolic BP levels measured by the tail-cuff method correlated well with those by the direct measurement through carotid artery catheter as reported (37). Systolic BP and heart rate were measured in 24-week-old transgenic and nontransgenic littermates before and 2 , $4,6,8$, and 10 hours after an intraperitoneal injection of an $\alpha_{1}$-adrenergic blocker, bunazosin $(15 \mu \mathrm{g} / \mathrm{g}$ body weight; Eizai Pharmaceuticals Inc., Tokyo, Japan), or a nonselective $\beta$-adrenergic blocker, propranolol $(6 \mu \mathrm{g} / \mathrm{g}$ body weight; Sigma Chemical Co., St. Louis, Missouri, USA), and before and 15, 30, and 60 minutes after a single intraperitoneal injection of a ganglionic blocker, hexamethonium $(3 \mu \mathrm{g} / \mathrm{g}$ body weight; Sigma Chemical Co.). We performed a single intracerebroventricular injection of SHU9119, a potent antagonist of $\alpha$ melanocyte-stimulating hormone $(\alpha-\mathrm{MSH})(0.05 \mu \mathrm{g} / 5$ $\mu \mathrm{L}$ per mouse) (Phoenix Pharmaceuticals, Mountain a

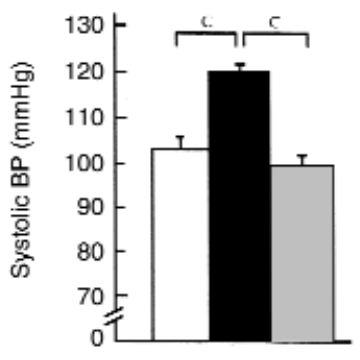

d

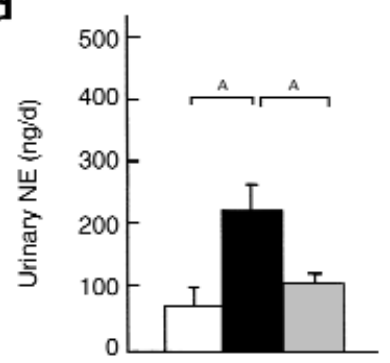

b

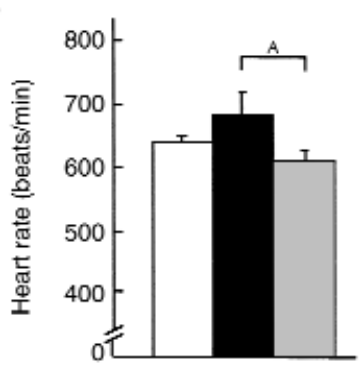

e

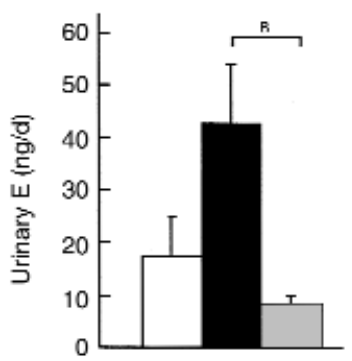

C

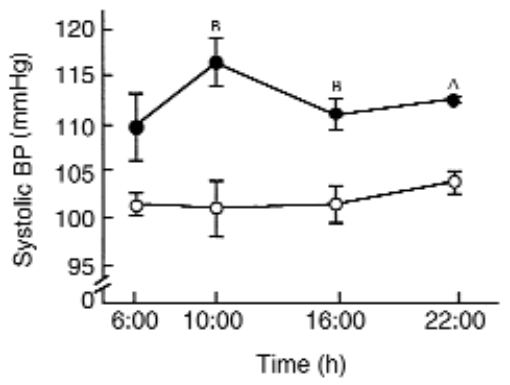

Figure 1

Profiles of transgenic skinny mice, ob/ob mice, and their control mice. Systolic BP (a) and heart rate (b) in 12-week-old transgenic skinny mice (black bars), ob/ob mice (shaded bars), and their control mice (open bars). (c) Daily profile of systolic BP in 12-week-old transgenic skinny mice (filled circles) and nontransgenic littermates (open circles). Urinary NE (c) and E (d) excretion levels in 12-week-old transgenic skinny mice (filled bars), ob/ob mice (shaded bars), and their control mice (open bars). ${ }^{A} P<0.05,{ }^{B} P<0.01$, and ${ }^{C} P<0.001$ compared with control mice assessed by 1-way ANOVA with Bonferroni Dunn test ( $\mathbf{a}, \mathbf{b}, \mathbf{d}, \mathbf{e})$, and by ANOVA with repeated measures analysis with Student's $t$ test at a given time $(\mathbf{c})$. 

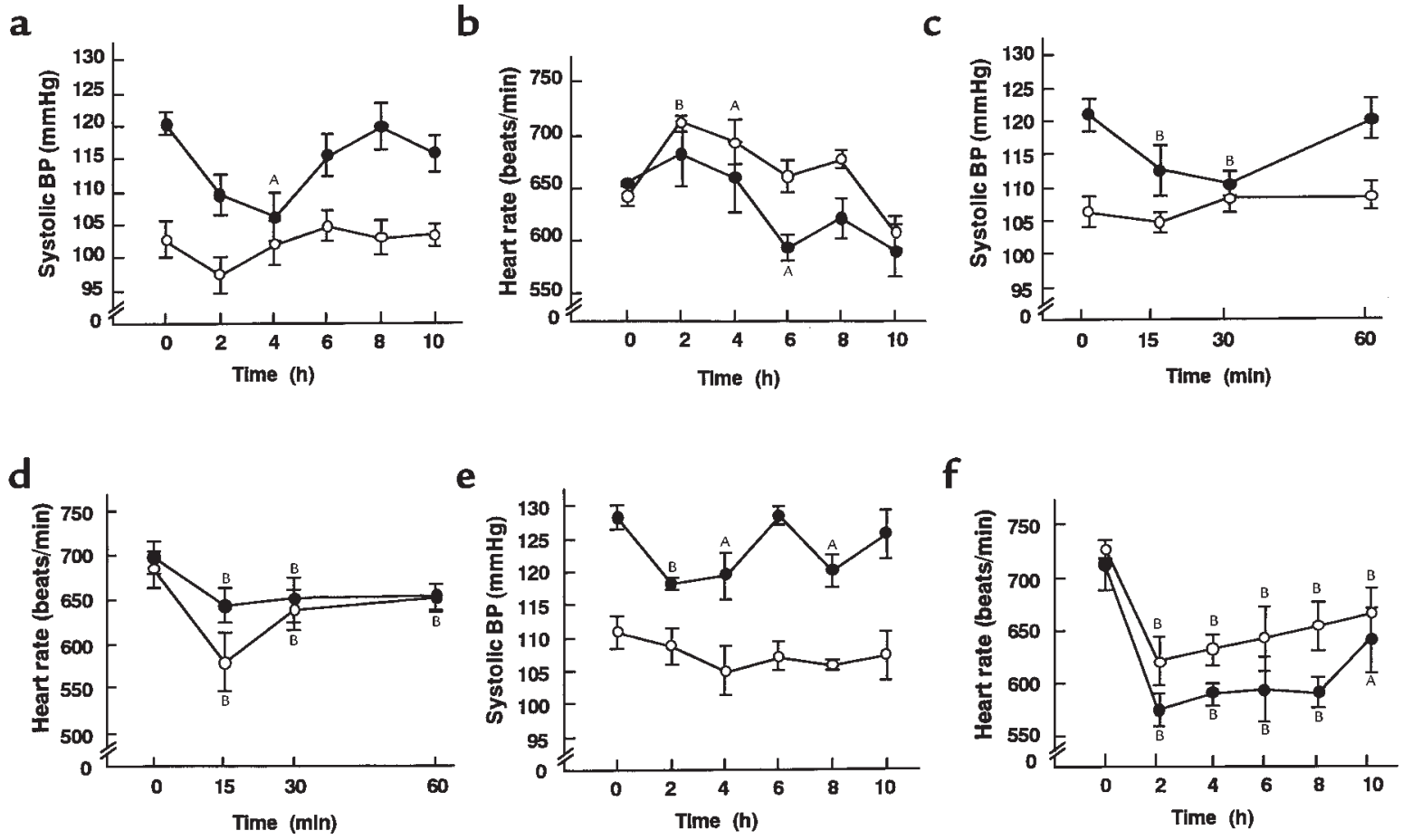

\section{Figure 2}

Effects of sympathetic blockades on systolic BP and heart rate in 12-week-old transgenic skinny mice and nontransgenic littermates. Effect of bunazosin on systolic BP (a) and heart rate (b). Effect of hexamethonium on systolic BP (c) and heart rate (d). Effect of propranolol on systolic $B P(\mathbf{e})$ and heart rate $(\mathbf{f}) .{ }^{A} P<0.05$ and ${ }^{B} P<0.01$ compared to the initial values.

View, California, USA) $(22,23,34)$ or artificial cerebrospinal fluid (aCSF) (15) through a 27-gauge stainless steel infusion cannula inserted into the lateral ventricle in mice under slight diethylether anesthesia, using the following coordinates: $4 \mathrm{~mm}$ anterior to the lamboidal suture, $2 \mathrm{~mm}$ lateral to the midline, and 2.5 $\mathrm{mm}$ vertically. Only the animals that showed increased food intake after the intracerebroventricular injection of SHU9119 were included in this study. The BP and heart rate were measured before and 3, 6, 9 hours after the injection at the onset of light phase.

Body weight and food intake measurements. Body weights of transgenic skinny mice, $o b / o b$ mice, KKA $y$ mice, and their control mice at 12 weeks of age were measured. Cumulative food intake was measured simultaneously in 12-week-old transgenic and nontransgenic littermates 8 hours after a single intracerebroventricular injection of SHU9119 or aCSF, when fed ad libitum.

Blood and urinary parameter measurements. Transgenic and nontransgenic littermates, $\mathrm{KK}^{y}$ and $\mathrm{KK}$ mice at 12 weeks of age were placed in metabolic cages that provide free access to tap water and food. Blood was sampled from the retro-orbital sinus of mice at 0900 hours. Plasma leptin concentrations in 12-week-old transgenic skinny mice, $o b / o b$ mice, and KKA $A^{y}$ mice and their control mice were determined using the RIA for mouse leptin (Linco Research Immunoassay, St. Charles, Missouri, USA). Serum osmolarity and hematocrit; serum concentrations of $\mathrm{Na}^{+}, \mathrm{K}^{+}$, and $\mathrm{Cl}^{+}$; serum creatinine; blood urea nitrogen; daily urine volume; urinary $\mathrm{Na}^{+}, \mathrm{K}^{+}$, and $\mathrm{Cl}^{+}$excretion; and water intake were measured according to the standard methods. Daily urinary catecholamine excretion was determined by reverse-phase HPLC (15).

Caloric restriction experiments. We observed that during a caloric restriction, hyperleptinemia are sustained in $\mathrm{Tg} /{ }^{+}: A^{y} /+$ mice (29), indicating that $\mathrm{Tg} /+: A^{y} /+$ mice provide the unique experimental model system to investigate the effect of leptin during fasting or food restriction. Based on the daily food intake of 12 -weekold + $/+, \mathrm{Tg} /+, A^{y} /+$, and $\mathrm{Tg} /+: A^{y} /+$ mice, they were provided with $60 \%$ of the amount of food consumed regularly as described elsewhere (29). During a 2-week food restriction, body weight, plasma leptin concentrations, and systolic BP were measured.

Leptin injection experiments. We examined the effect of continuous leptin administration on $\mathrm{BP}$ in $o b / o b$ mice. On the first day of the experiment, recombinant mouse leptin (PeproTech EC, London, United Kingdom) (2.4 $\mu \mathrm{g} / \mathrm{g}$ per day) or vehicle (saline) started to be infused into 12-week-old male $o b / o b$ mice and wild-type control littermates using osmotic minipump (Alzet model 1003D; Alza Corp, Palo Alto, California, USA) delivering $1 \mu \mathrm{L} / \mathrm{h}(100-\mu \mathrm{L}$ pump). Mice were anesthetized with pentobarbital (Nembtal, $50 \mathrm{mg} / \mathrm{kg}$ intraperitoneally), and an osmotic minipump was implanted subcutaneously in the midscapular region. During the 3-day infusion experiment, body weights, food intake, 
plasma leptin concentrations, and the tail-cuff systolic BP were measured.

We also examined the effect of chronic leptin administration on BPs in $A^{y} /+$ mice during the caloric restriction. Based on the daily food intake of 12 -week-old $A^{y} /+$ mice, they were provided with $60 \%$ of the amount of food consumed regularly. On the first day of food restriction, recombinant mouse leptin $(1.2 \mu \mathrm{g} / \mathrm{g}$ per day) or vehicle were infused into 12 -week-old $A^{y} /+$ mice using an osmotic minipump (Alzet model 2002) implanted subcutaneously, delivering $0.5 \mu \mathrm{L} / \mathrm{h}$ (200- $\mu \mathrm{L}$ pump). During the 10-day food restriction, body weights, plasma leptin concentrations, and the tail-cuff systolic BPs were measured.

Statistical analysis. Statistical significance was assessed by ANOVA with repeated measures analysis (Statview 4.01; Abacus Concepts Inc., Berkeley, California, USA), ANOVA with Bonferroni Dunn test, and Student's $t$ test, when applicable. All values were expressed as the mean \pm SEM.

\section{Results}

Systolic BP and heart rate in transgenic skinny mice and ob/ob mice. At 12 weeks of age, body weight of transgenic skinny mice was decreased significantly relative to nontransgenic littermates $(20.3 \pm 1.1$ vs. $26.1 \pm 0.9 \mathrm{~g} ; n=6 ; P<$ $0.01)$. On the other hand, leptin-deficient $o b / o b$ mice developed marked obesity relative to nontransgenic wild-type mice ( $47.9 \pm 1.1$ vs. $26.1 \pm 0.9 \mathrm{~g} ; n=6 ; P<0.001$ ). Plasma leptin concentrations were $60.6 \pm 14.4 \mathrm{ng} / \mathrm{mL}$ in transgenic skinny mice and were approximately 10 -fold higher than those in nontransgenic littermates ( $4.8 \pm 0.6$ $\mathrm{ng} / \mathrm{mL})(n=10 ; P<0.001)$. No significant amount of leptin was detected in $o b / o b$ mice. These data are consistent with previous reports $(24,25,28,29)$.

To elucidate the cardiovascular consequences of chronic hyperleptinemia, we measured systolic BP and heart rate in 12-week-old transgenic and nontransgenic littermates. At 0900 hours, the tail-cuff systolic BP was elevated significantly in transgenic skinny mice compared with nontransgenic littermates $(120.0 \pm 1.6$ vs. $102.7 \pm 2.7 \mathrm{mmHg} ; n=12 ; P<0.001$ ) (Figure 1a). Systolic BP elevation in transgenic skinny mice was observed sustained throughout the day $(n=3)$ (Figure $1 c)$. No significant difference in heart rate was noted between transgenic and nontransgenic littermates (684 \pm 35 vs. $642 \pm 10$ beats per minute; $n=12$ ) (Figure $1 \mathrm{~b}$ ). Heart rate tended to be decreased in $o b / o b$ mice (610 \pm 17 beats per minute) compared with their control mice.

Daily urinary catecholamine excretion in transgenic skinny mice and ob/ob mice. There was no significant difference between transgenic and nontransgenic mice in daily urine volume (data not shown). Daily urinary norepinephrine (NE) excretion was increased significantly in transgenic skinny mice compared with nontransgenic littermates $(224.0 \pm 43.3$ vs. $74.4 \pm 28.7 \mathrm{ng} / \mathrm{d} ; n=6 ; P<$ 0.05 ) (Figure 1d). Daily urinary epinephrine (E) excretion also tended to be increased in transgenic skinny mice relative to nontransgenic littermates $(42.7 \pm 11.5$ vs. $17.6 \pm 7.2 \mathrm{ng} / \mathrm{d} ; n=6$ ) (Figure 1e).

Daily urine volume of $o b / o b$ mice tended to be increased relative to their control mice $(1.7 \pm 0.2$ vs. 1.2 $\pm 0.1 \mathrm{~mL} / \mathrm{d} ; n=8)$. Daily urinary E excretion tended to be decreased in $o b / o b$ mice relative to their control mice $(8.7 \pm 1.1$ vs. $17.6 \pm 7.2 \mathrm{ng} / \mathrm{d} ; n=6)$, whereas no significant difference in daily urinary NE excretion was noted between genotypes $(107.3 \pm 15.2$ vs. $74.4 \pm 28.7 \mathrm{ng} / \mathrm{d}$; $n$ =6) (Figure 1, $\mathrm{d}$ and e). These results are consistent with a previous report (38).

Effects of sympathetic blockade on BP and heart rate in transgenic skinny mice. To explore the involvement of sympathetic activation in BP elevation in transgenic skinny mice, we examined the effect of sympathetic blockade on $\mathrm{BP}$ and heart rate in these animals. On examination of the dose-related effects of bunazosin, propranolol, and hexamethonium, we found that the maximal doses that do not affect BP in nontransgenic littermates are $15 \mu \mathrm{g} / \mathrm{g}$ body weight, $6 \mu \mathrm{g} / \mathrm{g}$ body weight, and $3 \mu \mathrm{g} / \mathrm{g}$ body weight, respectively. In transgenic skinny mice, systolic BP elevation was normalized 4 hours after the treatment with bunazosin at such a dose $(15 \mu \mathrm{g} / \mathrm{g}$ body weight $)$

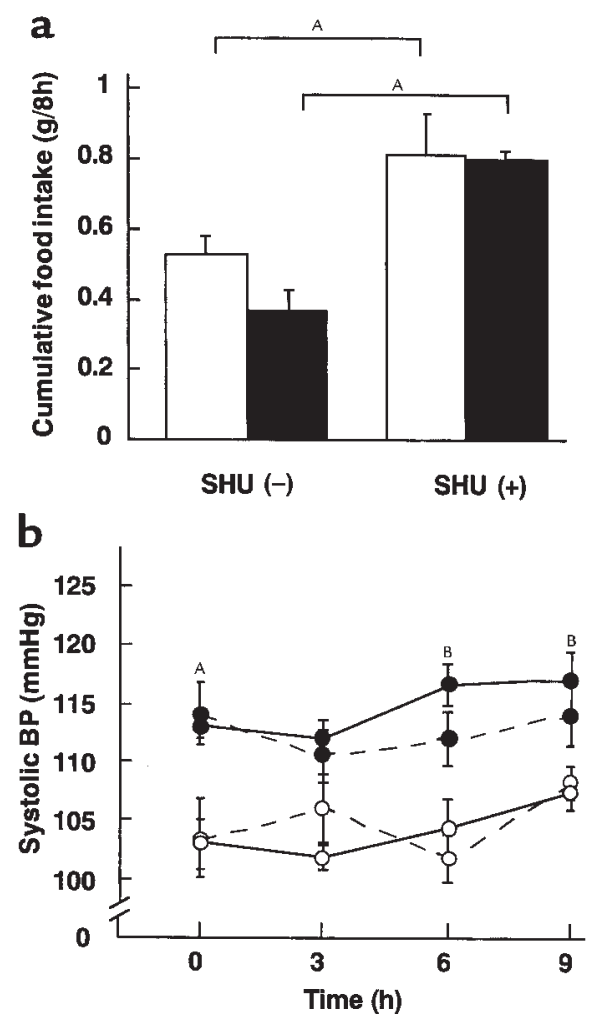

Figure 3

Effects of SHU9119 on cumulative food intake and systolic BP in 12week-old transgenic skinny mice and nontransgenic littermates. (a) Effect of SHU9119 on cumulative food intake in transgenic skinny mice (filled bars) and nontransgenic littermates (open bars). ${ }^{A} P<$ 0.05 compared with vehicle-treated groups. (b) Effect of SHU9119 on systolic BP in transgenic skinny mice (filled circles) and nontransgenic littermates (open circles). Mice treated with and without SHU9119 are depicted by solid and dotted lines, respectively. ${ }^{A} P<0.05$ and ${ }^{B} P<0.01$ compared with SHU9119-treated nontransgenic littermates. 

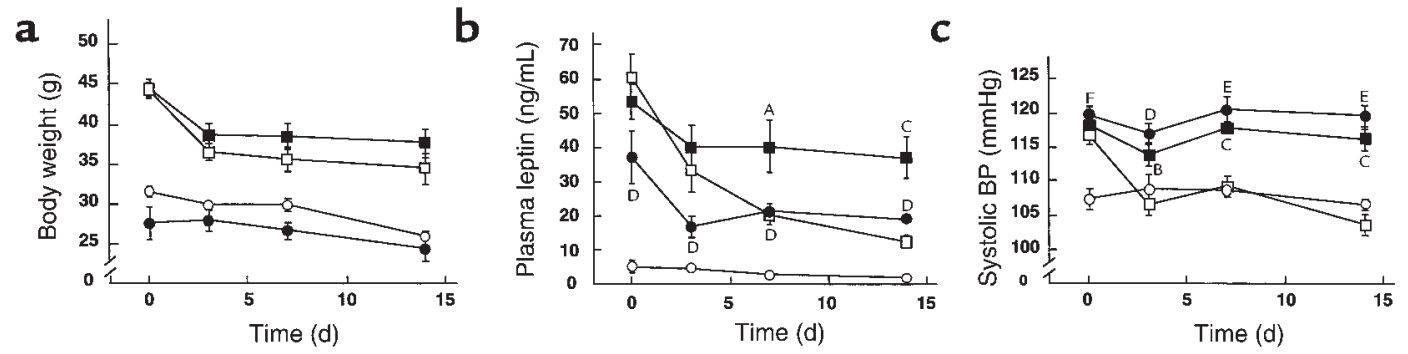

\section{Figure 4}

Effects of a 2-week caloric restriction on body weights, plasma leptin concentrations, and systolic BPs in 12-week-old F1 animals $(+/+, \mathrm{Tg} /+$, $A^{y} /+$, and $\mathrm{Tg} /+: A y /+$ mice). (a) Time course of body weights of $+/+$ (open circles), $\mathrm{Tg} /+$ (filled circles), $A^{y} /+$ (open boxes), and Tg/+:Ay/+ (filled boxes) mice during the caloric restriction. (b) Time course of plasma leptin concentrations in $+/+$ (open circles), $\mathrm{Tg} /+($ filled circles), $A^{y} /+$ (open boxes), and $\mathrm{Tg} /+: A^{y} /+$ (filled boxes) mice. (c) Time course of systolic BPs in +/+ (open circles), $\mathrm{Tg} /+$ (filled circles), $A^{y} /+($ open boxes), and $\mathrm{Tg} /+: A^{y} /+$ (filled boxes) mice. ${ }^{\mathrm{D} P}<0.05,{ }^{\mathrm{E}} P<0.01$, and ${ }^{\mathrm{F}} P<0.001(\mathrm{Tg} /+$ mice compared with $+/+$ mice $)$, and ${ }^{\mathrm{A}} P<0.05,{ }^{\mathrm{B}} P<$ 0.01 , and ${ }^{C} P<0.001\left(\mathrm{Tg} /+: A^{y} /+\right.$ mice compared with $A^{y} /+$ mice $)$ assessed by ANOVA with repeated measures analysis with Student's $t$ test at a given time.

that does not affect $\mathrm{BP}$ in nontransgenic littermates (Figure 2a). No significant change in heart rate was noted between genotypes treated with bunazosin (Figure 2b). Hexamethonium at a dose of $3 \mu \mathrm{g} / \mathrm{g}$ body weight also abolished significantly systolic BP elevation in transgenic skinny mice 15 and 30 minutes after the treatment, whereas no significant changes were noted in nontransgenic littermates (Figure 2, c and d). Furthermore, systolic BP elevation was attenuated significantly in transgenic skinny mice that received a single intraperitoneal injection of propranolol at a dose of $6 \mu \mathrm{g} / \mathrm{g}$ body weight, when heart rates were reduced significantly in both genotypes (Figure 2, e and f).

Blood and urinary parameters and heart and kidney weights in transgenic skinny mice. To explore the effect of chronic hyperleptinemia on body fluid homeostasis and electrolyte balance, we measured blood and urinary parameters in transgenic skinny mice. No significant differences were noted between transgenic and nontransgenic littermates in daily urine volume and water intake; serum osmolarity and hematocrit; serum concentrations of $\mathrm{Na}^{+}, \mathrm{K}^{+}$, and $\mathrm{Cl}^{+}$; serum creatinine; blood urea nitrogen; and urinary $\mathrm{Na}^{+}, \mathrm{K}^{+}$, and $\mathrm{Cl}^{+}$excretion (data not shown). There were no appreciable differences in the weights of heart and kidney between transgenic and nontransgenic littermates (data not shown).

Effects of hypothalamic melanocortin system blockade on BP elevation in transgenic skinny mice. To explore the role of hypothalamic melanocortin system in BP elevation in transgenic skinny mice, we examined the effect of a single intracerebroventricular injection of SHU9119 on systolic BP in these animals. When treated with aCSF, cumulative food intake of transgenic skinny mice was smaller than that of nontransgenic littermates as reported (28) $(0.37 \pm 0.06$ vs. $0.51 \pm 0.06 \mathrm{~g} / 8 \mathrm{~h} ; n=4)$ (Figure $3 \mathrm{a}$ ). On the other hand, a single intracerebroventricular injection of SHU9119 at a dose of 0.05 $\mu \mathrm{g}$ per mouse caused a significant increase in cumulative food intake in both transgenic and nontransgenic littermates during 8 hours at the onset of the light phase $(0.81 \pm 0.02$ vs. $0.81 \pm 0.17 \mathrm{~g} / 8 \mathrm{~h} ; n=4)$ (about 2- fold increase in both genotypes relative to aCSF-treated groups) $(P<0.05)$ (Figure $3 a)$. Nevertheless, no significant changes in systolic $\mathrm{BP}$ were noted in transgenic and nontransgenic littermates up to 8 hours after the SHU9119 treatment (Figure 3b).

Body weight, plasma leptin concentrations, systolic BP, and urinary catecholamine excretion in $K K$ and $K K A^{y}$ mice. To explore further the possible role of leptin in obesityrelated hypertension, we examined the cardiovascular phenotypes of genetically obese KKAy mice. At 12 weeks of age, $\mathrm{KK}^{y}$ mice developed obesity relative to age-matched control KK mice ( $39.8 \pm 1.2$ vs. $31.3 \pm 0.3$ g; $n=6 ; P<0.001)$. Plasma leptin concentrations in $\mathrm{KK} A^{y}$ mice were $27.8 \pm 1.1 \mathrm{ng} / \mathrm{mL}$ and were approximately 4.5 -fold higher than those in KK mice $(6.3 \pm 1.0$ $\mathrm{ng} / \mathrm{mL})(n=10 ; P<0.001)$.

At 0900 hours, systolic BP was elevated significantly in $\mathrm{KK} A^{y}$ mice compared with KK mice (116.4 \pm 1.4 vs. $109.5 \pm 1.2 \mathrm{mmHg} ; n=10 ; P<0.01)$. Systolic BP elevation in $\mathrm{KK} A^{y}$ mice was also sustained throughout the day (data not shown). No significant difference in heart rate was noted between KK and KKA $y$ mice (479.5 \pm 14.6 vs. $489.1 \pm 19.7$ beats per minute; $n=10$ ). Daily urine volume of $\mathrm{KKA}^{y}$ mice was significantly larger than that of KK mice $(14.6 \pm 1.2$ vs. $2.6 \pm 0.7 \mathrm{~mL} / \mathrm{d} ; n=$ 4; $P<0.001)$. Daily urinary NE and E excretion was increased significantly in $\mathrm{KK} A^{y}$ mice relative to $\mathrm{KK}$ mice (NE, $434.9 \pm 42.0$ vs. $221.2 \pm 69.9 \mathrm{ng} / \mathrm{d}[n=4 ; P<$ $0.05]$; E, $37.3 \pm 4.6$ vs. $7.7 \pm 1.5 \mathrm{ng} / \mathrm{d}[n=4 ; P<0.001]$ ).

Body weight change, plasma leptin concentrations, and systolic BP in $+/+, \mathrm{Tg} /+, A^{y} /+$, and $\mathrm{Tg} /+: A^{y} /+$ mice during caloric restriction. We reported that at younger ages (i.e., at 4 weeks of age), $\mathrm{Tg} /+: \mathrm{Ay} /+$ mice exhibit skinny phenotype similar to that of $\mathrm{Tg} /+$ mice but that at older ages (i.e. at 12 week of age), they develop obesity similar to that of $A y /+$ mice (29). To assess the involvement of hyperleptinemia in BP elevation in obese $\mathrm{KKA}^{\mathrm{y}}$ mice and to explore the role of leptin in BP decrease during weight loss (5-8), we examined the cardiovascular phenotypes of 12-week-old +/+, $\mathrm{Tg} /+, \mathrm{A} / /+$, and $\mathrm{Tg} /+$ :Ay $/+$ mice during a caloric restriction. Body weights of $\mathrm{Tg} /+: \mathrm{A} / \mathrm{H}$ and 
a

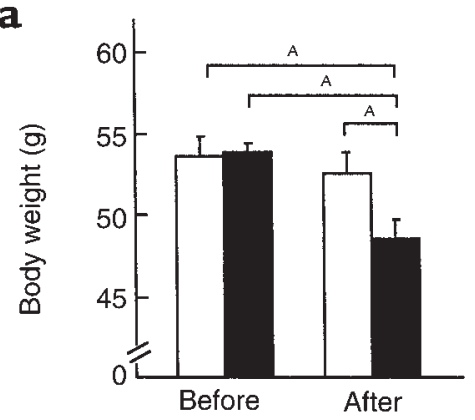

c

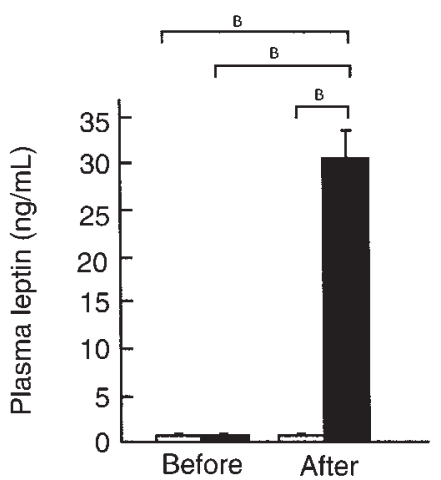

b

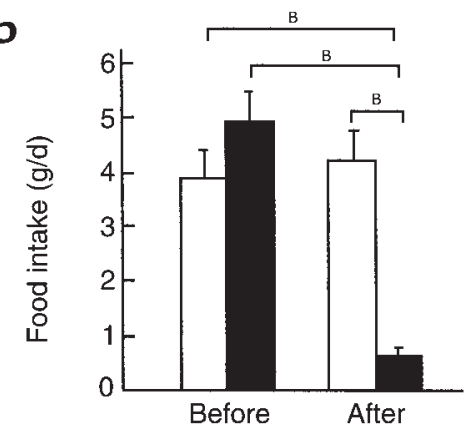

d

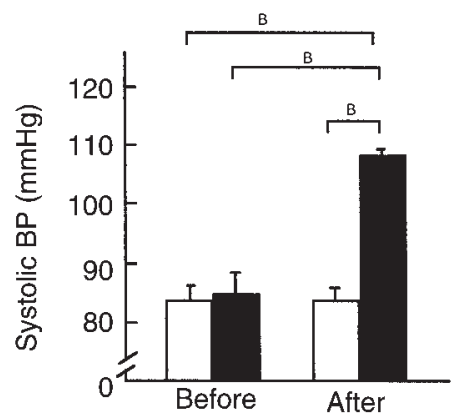

Figure 5

Effects of a 3-day leptin administration on body weights, plasma leptin concentrations, and systolic BPs in 12-week-old male $o b / o b$ mice and control littermates. (a) Body weights of $o b / o b$ mice before and 3 days after the treatment. (b) Food intake of ob/ob mice before and 3 days after the treatment. (c) Plasma leptin concentrations in ob/ob mice before and 3 days after the treatment. (d) Systolic BPs of $o b / o b$ mice before and 3 days after the treatment. The $o b / o b$ mice treated with leptin or vehicle are indicated by filled and open bars, respectively. ${ }^{A} P<0.05,{ }^{B} P<0.01$ versus vehicle-treated groups assessed by ANOVA with repeated measures analysis with Student's $t$ test.
$\mathrm{A}^{\mathrm{y}} /+$ mice $(44.7 \pm 1.2$ and $44.5 \pm 0.8 \mathrm{~g}$, respectively) were significantly greater than those of $+/+$ and $\mathrm{Tg} /+$ mice $(31.8 \pm 0.7$ and $27.8 \pm 2.1$ g, respectively) $(n=7)$ (Figure 4a). No significant difference in body weight was noted between $\mathrm{Tg} /+\mathrm{A}^{\mathrm{y}} /+$ and $\mathrm{A}^{\mathrm{y}} /+$ mice. After a 2 -week caloric restriction, body weights of $\mathrm{Tg} /+$ and $+/+$ mice were $16.1 \pm 2.4$ and $13.4 \pm 2.0 \%$ less, respectively, than those before the experiment (Figure 4a). Body weights of $\mathrm{Tg} /+: \mathrm{A}^{\mathrm{y}} /+$ and $\mathrm{A}^{\mathrm{y}} /+$ mice after the caloric restriction were also decreased significantly $(19.4 \pm 2.7$ and $23.9 \pm$ $1.7 \%$ less, respectively) relative to those before the caloric restriction (Figure 4a). After the caloric restriction, no significant difference in body weight was noted among +/+, $\mathrm{A}^{\mathrm{y} /+}$, and $\mathrm{Tg} /+: \mathrm{A}^{\mathrm{y}} /+$ mice.

Plasma leptin concentrations in 12-week-old $\mathrm{Tg} /+$, $A^{y} /+$, and $\mathrm{Tg} /+: A^{y} /+$ mice were $37.3 \pm 7.9,60.4 \pm 7.0$, and $53.4 \pm 5.2 \mathrm{ng} / \mathrm{mL}$, respectively, and were significantly higher than those in $+/+$ mice $(5.3 \pm 1.9 \mathrm{ng} / \mathrm{mL})(P<0.05$, $n=7$ ) (Figure $4 \mathrm{~b}$ ). No significant difference in plasma leptin concentration was noted between $\mathrm{Tg} /+: A^{y} /+$ and $A^{y} /+$ mice. Plasma leptin concentrations in $+/+$ and $A^{y} /+$ mice after a 2 -week caloric restriction $(2.1 \pm 0.4$ and 12.7 $\pm 2.0 \mathrm{ng} / \mathrm{mL}$, respectively) were approximately $60 \%$ and $80 \%$ lower, respectively, than those before the caloric restriction (Figure 4b). On the other hand, after the caloric restriction, plasma leptin concentrations remained high in $\mathrm{Tg} /+$ and $\mathrm{Tg} /+: A^{y} /+$ mice $(19.3 \pm 0.1$ and $37.3 \pm 5.9 \mathrm{ng} / \mathrm{mL}$, respectively); it is because of hepatic overproduction of leptin in $\mathrm{Tg} /+$ and $\mathrm{Tg} /+: A^{y} /+$ mice.

Before the caloric restriction, systolic BP was elevated significantly in $\mathrm{Tg} /+, A^{y} /+$, and $\mathrm{Tg} /+^{+}: A^{y} /+$ mice $(119.8 \pm$ $1.3,116.8 \pm 1.4$, and $118.2 \pm 1.1 \mathrm{mmHg}$, respectively) rel- ative to $+/+$ mice $(107.4 \pm 1.5 \mathrm{mmHg})(n=7)$ (Figure $4 \mathrm{c})$. No significant difference in systolic $B P$ was noted among $\mathrm{Tg} /+, A^{y} /+$, and $\mathrm{Tg} /+: A^{y} /+$ mice. After the caloric restriction, systolic BP elevation was reversed in $A^{y} /+$ mice $(103.7 \pm 1.5 \mathrm{mmHg})$, which is roughly comparable to that in $+/+$ mice $(106.7 \pm 0.7 \mathrm{mmHg})$. On the other hand, systolic BP elevation was sustained in $\mathrm{Tg} /+: A^{y} /+$ mice after the caloric restriction $(116.3 \pm 1.7 \mathrm{mmHg}$ ) (Figure $4 \mathrm{c}$ ).

Leptin injection experiments. To assess whether hyperleptinemia during adulthood plays a major role in the development of BP elevation in transgenic skinny mice, we examined the effect of continuous leptin administration on BP in $o b / o b$ mice $(n=6)$. After a 3-day infusion, body weights of $o b / o b$ mice treated with leptin decreased significantly relative to vehicle-treated animals (48.6 \pm 1.2 vs. $52.6 \pm 1.3 \mathrm{~g}, P<0.05$ ) (Figure 5a). Food intake of leptin-treated $o b / o b$ mice was also decreased significantly compared with vehicle-treated groups at the end of the experiment $(0.6 \pm 0.2$ vs. $4.2 \pm 0.6 \mathrm{~g} / \mathrm{d} ; P<0.01)$ (Figure $5 b)$. Plasma leptin concentrations were elevated in leptintreated $o b / o b$ mice 3 days after the treatment (Figure 5c). Three days after the treatment, plasma leptin concentrations were $30.6 \pm 2.9 \mathrm{ng} / \mathrm{mL}$ in leptin-treated $o b / o b$ mice, whereas no significant amount of leptin was detected in vehicle-treated groups. During this experiment, systolic $\mathrm{BP}$ was unchanged in vehicle-treated $o b / o b$ mice. By contrast, leptin administration increased BP by as much as $25 \mathrm{mmHg}$ in $o b / o b$ mice (Figure $5 \mathrm{~d}$ ). These observations demonstrate that leptin can reverse the otherwise lowered $\mathrm{BP}$ in genetically obese leptin-deficient $o b / o b$ mice.

To see whether weight loss does not lower BP in calorically restricted $A^{y} /+$ mice when plasma leptin concentra- 
tions are elevated, we studied the effect of chronic leptin administration on BP in $A^{y} /+$ mice during the caloric restriction $(n=6)$. During the 10 -day food restriction, body weights of $A^{y} /+$ mice treated with leptin decreased comparably to those of vehicle-treated animals (Figure 6a). Plasma leptin concentrations were reduced in vehicletreated $A^{y} /+$ mice during the caloric restriction, whereas they remained high in leptin-treated $A^{y} /+$ mice (Figure 6b). Ten days after the caloric restriction, plasma leptin concentrations were $51.3 \pm 10.1$ and $13.6 \pm 1.2 \mathrm{ng} / \mathrm{mL}$ in leptin- and vehicle-treated groups, respectively $(P<0.05)$. During the experiment, systolic BP was decreased in vehicle-treated $A y /+$ mice, whereas no significant change in $\mathrm{BP}$ was noted in leptin-treated $A y /+$ mice (Figure $6 c$ ). The systolic BPs in leptin- and vehicle-treated $A^{y} /+$ mice were $115.8 \pm 1.2$ and $101.9 \pm 1.6 \mathrm{mmHg}$, respectively $(P<0.001)$. These observations demonstrate that with chronic hyperleptinemia, BP remains high in $A^{y} /+$ mice even during the caloric restriction, thereby supporting the notion that maintenance of hyperleptinemia in the adult mice is sufficient to explain BP elevation in $A^{y} /+$ mice.

\section{Discussion}

In this study, we have demonstrated that BP is elevated significantly in transgenic skinny mice relative to nontransgenic littermates. These findings indicate that chronic hyperleptinemia can lead to a significant BP elevation in conscious mice. This is also consistent with the data that chronic as well as acute treatment of leptin can increase BP in conscious rats and in $o b / o b$ mice (13, 39-41; Figure 5). On the other hand, there is a report that acute leptin treatment has no effect on BP in anesthetized rats (12). Transgenic skinny mice exhibit a significant increase in urinary catecholamine excretion, suggesting chronic sympathetic activation. Furthermore, BP elevation is abolished in transgenic skinny mice by treatment with the $\alpha_{1}$-adrenergic, sympathetic ganglionic, and nonselective $\beta$-adrenergic blockers at such doses that do not affect BP in nontransgenic littermates. These findings suggest that BP elevation in transgenic skinny mice is mediated through the sympathetic activation (Figure 7a).
Several studies have demonstrated that central administration of leptin can increase uncoupling protein-1 mRNA expression in the brown adipose tissue (BAT) $(14,23)$ and catecholamine secretion (15), suggesting that sympathetic activation of leptin is mediated primarily via the central nervous system. We postulate that BP elevation in transgenic skinny mice is also due primarily to the central effect of leptin. This notion is consistent with previous reports that a single intracerebrovascular injection of leptin can increase BP in rats $(40,41)$. The discussion, however, does not rule out the possibility that leptin can increase BP via peripheral mechanisms, because leptin receptor is expressed in peripheral tissues including vascular endothelial cells and adrenal medulla (42-44).

We and others demonstrated that a single intracerebrovascular injection of SHU9119 abolishes the leptininduced decrease in food intake and body weight in rats and postulated that hypothalamic melanocortin system is involved in the satiety effect of leptin $(22,23)$. In this study, treatment with SHU9119 increases significantly cumulative food intake in transgenic and nontransgenic littermates relative to vehicle-treated groups, suggesting that a marked decrease in food intake in transgenic skinny mice is also mediated at least partly via hypothalamic melanocortin system. On the other hand, no significant changes in BP are noted in both genotypes after the SHU9119 treatment. These findings suggest that decreased food intake and BP elevation in transgenic skinny mice are mediated via different mechanisms, i.e., leptin may exert its satiety effect via hypothalamic melanocortin system, whereas it can induce a significant BP elevation independently (Figure 7a). In this regard, it has been recently suggested that the acutely increased mean arterial pressure in response to a single intracerebrovascular injection of leptin may be mediated by proopiomelanocortin products (45). It is conceivable that leptin can acutely increase BP via hypothalamic melanocortin system; however chronic hyperleptinemia can increase BP independently. We previously demonstrated that a single intracerebrovascular injection of
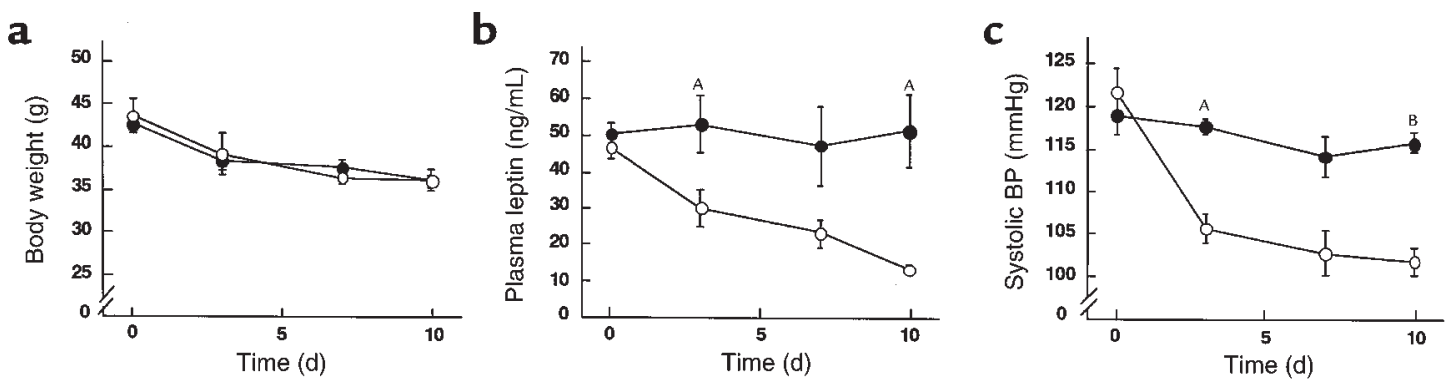

\section{Figure 6}

Effects of chronic leptin administration on BPs in 12-week-old male $A y /+$ mice during a 10-day caloric restriction. (a) Time course of body weights of $A^{y} /+$ mice treated with leptin or vehicle. (b) Time course of plasma leptin concentrations in $A^{y} /+$ mice treated with leptin or vehicle. (c) Time course of systolic BPs in $A^{y} /+$ mice treated with leptin or vehicle. The $A^{y} /+$ mice treated with leptin or vehicle are indicated by filled and open circles, respectively. ${ }^{A} P<0.05,{ }^{B} P<0.001$ versus vehicle-treated groups assessed by ANOVA with repeated measures analysis with Student's $t$ test at a given time. 
a
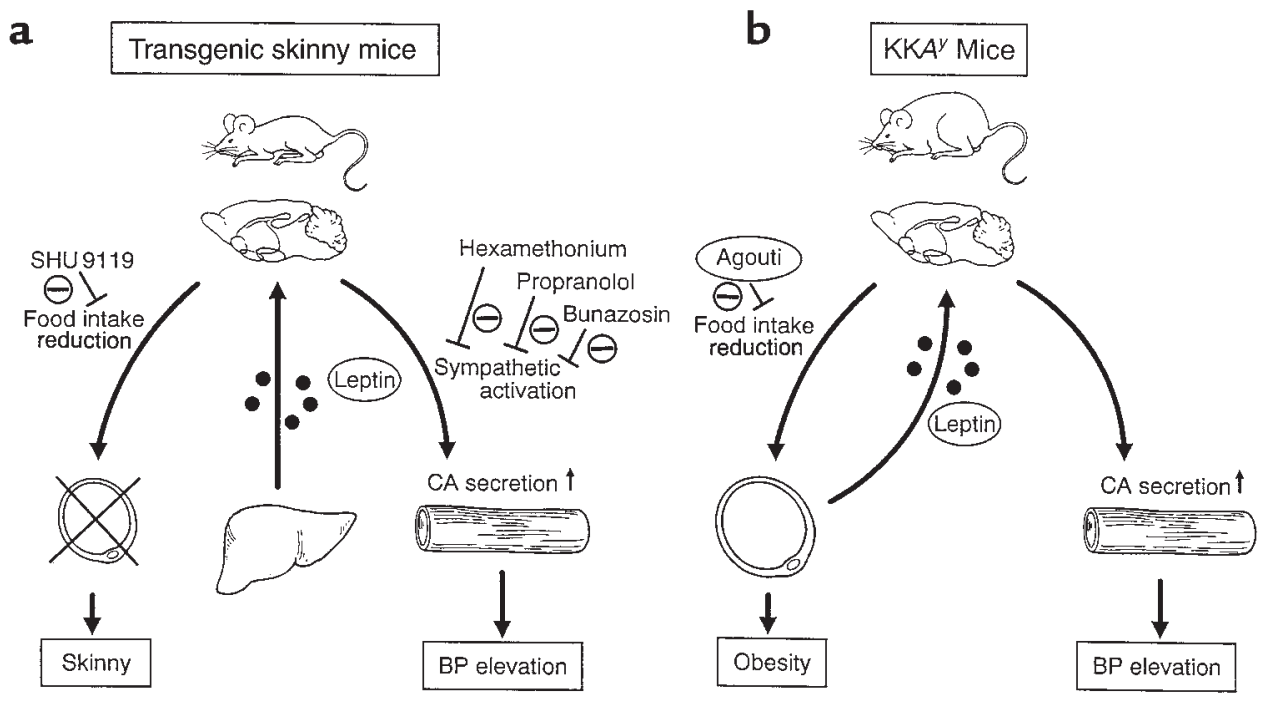

\section{Figure 7}

Possible mechanisms for the leptin-induced BP elevation in transgenic skinny mice (a) and KKAy mice (b). In transgenic skinny mice (a), leptin is oversecreted ectopically from the liver into the circulation, which causes the skinny phenotype with decreased food intake and a significant BP elevation with increased catecholamine production. They are hypoinsulinemic with hypersensitivity to insulin (28). Decrease in food intake is reversed by SHU9119, whereas BP elevation is not abolished by SHU9119 but by bunazosin, propranolol, and hexamethonium. In KKAy mice (b), leptin is oversecreted from the adipose tissue into the circulation, which causes significant BP elevation with increased catecholamine production, although they are hyperphagic owing to the antagonism of hypothalamic melanocortin system by the agouti protein. They are hyperinsulinemic with marked resistance to insulin $(30,31)$. CA, catecholamine.

SHU9119 abolishes the leptin-induced increase in UCP1 mRNA expression in the BAT in rats (23). On the other hand, Haynes et al. have reported that leptin can increase sympathetic nerve activity through the activation of hypothalamic melanocortin system, whereas it may increase sympathetic nerve traffic to the BAT independently (46). These findings suggest that some but not all of the leptin-induced sympathetic activation are mediated via hypothalamic melanocortin system. Because central administration of neuropeptide $\mathrm{Y}$ (NPY) reduces $\mathrm{BP}$ in rats and dogs $(47,48)$, decreased hypothalamic NPY production by exogenous administration of leptin (49) and in transgenic skinny mice (Y. Ogawa et al, unpublished data) might be involved in hypertensive effect of leptin.

The KKA $A^{y}$ mice develop a maturity-onset obesity and diabetes syndrome because of the antagonism of hypothalamic melanocortin system by the agouti protein (30, 31 ), thereby conferring resistance to the satiety effect of leptin (32). This study demonstrated significant increases in BP and urinary catecholamine excretion in obese $\mathrm{KK} A^{y}$ mice with hyperleptinemia (Figure $7 \mathrm{~b}$ ). Furthermore, after the caloric restriction, BP elevation is reversed in $A y /+$ mice in parallel with a significant reduction in plasma leptin concentrations, whereas no such changes are noted in $\mathrm{Tg} /+: A y /+$ mice with sustained hyperleptinemia. These findings, taken together, suggest that chronic hyperleptinemia may be involved in BP elevation in obese $\mathrm{KK} A^{y}$ mice. Thus, obese $\mathrm{KK} A^{y}$ mice may provide the unique opportunities to investigate the pathophysiological role of leptin in obesity-related hypertension; they develop obesity owing to their resistance to the satiety effect of leptin and develop BP elevation owing possibly to their sensitivity to hypertensive effect of leptin (Figure 7b). This is also consistent with the hypothesis described earlier here that in transgenic skinny mice, leptin can exert its satiety effect via hypothalamic melanocortin system but induce BP elevation independently. There are a variety of phenotypic differences between yellow agouti mice such as KKA $A^{y}$ mice and leptin signaling-deficient $o b / o b$ and $d b / d b$ mice (10, 50-52). In contrast with $o b / o b$ and $d b / d b$ mice, yellow agouti mice show a maturity-onset obesity and diabetes syndrome, normal tone of hypothalamic-pituitary-adrenal axis, increased linear growth, normal thermoregulation against cold stress, and normal locomotor activity (30, $31,50-52)$, indicating that some of leptin actions are independent of hypothalamic melanocortin system. Our data herein suggest that hypertensive effect of leptin might be one of such actions.

The mechanism of obesity-related hypertension is not clear at present. It has been suggested that obesity-related hypertension is secondary to insulin resistance and/or hyperinsulinemia $(2,3,7)$. Lansberg and Krieger have proposed that hyperinsulinemia causes sodium retention in the kidney as well as increases vascular resistance, thereby leading to an significant BP elevation in obese subjects (3). On the other hand, transgenic skinny mice exhibit increased glucose metabolism and insulin sensitivity with a significant reduction in plasma insulin concentrations compared with nontransgenic littermates (28). Taken together, the data of this study indicate that 
chronic hyperleptinemia alone can cause a significant BP elevation in mice without obesity, insulin resistance, and hyperinsulinemia (Figure 7a). Several studies revealed that there is a significant correlation between plasma insulin and leptin concentrations (53) and that insulin increases synthesis and secretion of leptin in the adipose tissue in vivo (54). We hypothesize that obesity- and/or hyperinsulinemia-induced hyperleptinemia may increase sympathetic nerve activity, thus contributing to a significant BP elevation in obese subjects.

Weight reduction is an effective and nonpharmacologic method to lower BP in obese hypertensive subjects; however, the mechanism responsible for it has remained to be elucidated. Several studies suggested that the BP decrease after weight loss is related to the suppression of sympathetic nerve activity in rats and humans (6-8). In this study, after the caloric restriction, $\mathrm{BP}$ elevation is reversed in $A^{y} /+$ mice in parallel with a reduction in plasma leptin concentrations, whereas no significant changes are noted in $\mathrm{Tg} /+: A^{y} /+$ mice. We also examined the effect of chronic leptin administration on $\mathrm{BP}$ in $A^{y} /+$ mice during a caloric restriction and observed that with continuous hyperleptinemia, weight loss does not lower BP in calorically restricted $A y /+$ mice. These observations suggest that hyperleptinemia alone can increase BP even during a caloric restriction. It is also tempting to speculate that like starvation-induced suppression of neuroendocrine and immune functions $(55,56)$, the BP decrease after weight loss is due partly to leptin deficiency.

The clinical features of obesity-related hypertension also include sodium retention with a concomitant increase in blood volume and cardiac output (3). It seems, however, that transgenic skinny mice and obese $\mathrm{KK} A^{y}$ mice develop no such manifestations. Thus, chronic hyperleptinemia is not sufficient to recapitulate all signs and symptoms of obesity-related hypertension. Previously, we identified a nonsense mutation of leptin receptor in obese spontaneously hypertensive Koletsky $\left(f a^{k} / f a^{k}\right)$ rats (57). The rats have been maintained on the SHR background, which explains their severe hypertension. Furthermore, obese Zucker fatty rats ( $f a / f a$ rats) with leptin receptor mutations $(17,58)$ exhibit marked BP elevation (59). In Zucker fatty rats, increased BP appears to be associated with the obese genotype (59). These observations suggest that the genetic factors might affect BP in obesity independently of leptin signaling. Thus, hyperleptinemia in combination with other factors should contribute to the overall profile of obesity-related hypertension.

Our data suggest that leptin treatment may cause BP elevation in humans. In this regard, Farooqi et al. have reported the effects of recombinant human leptin in a child with congenital leptin deficiency and found no significant BP differences before and after the leptin treatment (60). Furthermore, no significant BP change was reported in obese and lean adults treated with leptin (61). Thus, there might be species difference in the leptin-induced BP increase.
In conclusion, this study demonstrates BP elevation in transgenic skinny mice and $\mathrm{KK} A^{y}$ mice, both of which are hyperleptinemic, thereby raising the possibility that leptin may play a role in the pathogenesis of some forms of obesity-related hypertension.

\section{Acknowledgments}

We thank Y. Yamori, G. Katsuura, S. Yura, and J. Hirao$\mathrm{ka}$ for discussions. The authors also acknowledge Y. Isa, Y. Nakajima, and K. Hiramatsu for secretarial assistance. This work is supported in part by research grants from the Japanese Ministry of Education, Science, Sports, and Culture; the Japanese Ministry of Health and Welfare; the Yamanouchi Foundation for Research on Metabolic Disorders; the Foundation for Total Health Promotion 1998; The Naito Foundation; The Mitsubishi Foundation; The Uehara Memorial Foundation; and Research for the Future of Japanese Society for the Promotion of Science (JSPS-RFTF 96100204 and 98L00801).

1. Kannel, W.B., Brand, M., Skinner, Jr., J.J., Sawber, T.R., and McNamara, P.M. 1967. The relation of adiposity to blood pressure and development of hypertension: the Framingham study. Ann. Intern. Med. 67:48-59.

2. Reaven, G.M. 1988. Role of insulin resistance in human disease. Diabetes. 37:1595-1607.

3. Landsberg, L., and Krieger, D.R. 1989. Obesity, metabolism, and the sympathetic nervous system. Am. J. Hypertension. 2:125S-132S.

4. Mark, A.L., Correia, M., Morgan, D.A., Shaffer, R.A., and Haynes, W.G. 1999. Hypertension 33:537-541.

5. Rocchini, A.P., et al. 1989. The effect of weight loss on the sensitivity of blood pressure to sodium in obese adolescents. N. Engl. J. Med. 31:580-585.

6. Overton, J.M., VanNess, J.M., and Casto, R.M. 1996. Food restriction reduces sympathetic support of blood pressure in spontaneously hypertensive rats. J. Nutri. 127:655-660.

7. Kushiro, T., et al. 1991. Role of sympathetic activity in blood pressure reduction with low calorie regimen. Hypertension. 17:965-968.

8. Ikeda, T., Gomi, T., Hirawa, N., Sakurai, J., and Yoshikawa, N. 1996. Improvement of insulin sensitivity contributes to blood pressure reduction after weight loss in hypertensive subjects with obesity. Hypertension. 27:1180-1186.

9. Spiegelman, B.M., and Flier, J.S. 1996. Adipogenesis and obesity: rounding out the big picture. Cell. 87:377-389.

10. Zhang, Y., et al. 1994. Positional cloning of the mouse obese gene and its human homologue. Nature. 372:425-432.

11. Collins, S., et al. 1996. Role of leptin in fat regulation. Nature. 380:677.

12. Haynes, W.G., Morgan, D.A., Walsh, S.A., Mark, A.L., and Sivitz, W.I. 1997. Receptor-mediated regional sympathetic nerve activation by leptin. J. Clin. Invest. 100:270-278.

13. Dunbar, J.C., Hu, Y., and Lu, H. 1997. Intracerebroventricular leptin increases lumbar and renal sympathetic nerve activity and blood pressure in normal rats. Diabetes. 46:2040-2043.

14. Scarpace, P.J., Matheny, M., Pollock, B.H., and Tümer, N. 1997. Leptin increases uncoupling protein expression and energy expenditure. Am.J. Physiol. 273:E226-E230.

15. Satoh, N., et al. 1999. Sympathetic activation of leptin via the ventromedial hypothalamus: leptin-induced increase in catecholamine secretion. Diabetes. 48:1787-1793.

16. Tartaglia, L.A., et al. 1995. Identification and expression cloning of a leptin receptor, OB-R. Cell. 83:1263-1271.

17. Takaya, K., et al. 1996. Molecular cloning of rat leptin receptor isoform complementary DNAs: identification of a missense mutation in Zucker fatty $(f a / f a)$ rats. Biochem. Biophys. Res. Commun. 225:75-83.

18. Schwartz, M.W., Seeley, R.J., Campfield, L.A., Burn, P., and Baskin, D.G. 1996. Identification of target of leptin action in rat hypothalamus. J. Clin. Invest. 98:1101-1106.

19. Fei, H., et al. 1997. Anatomic localization of alternatively spliced leptin receptors (Ob-R) in mouse brain and other tissues. Proc. Natl. Acad. Sci. USA. 94:7001-7005.

20. Satoh, N., et al. 1997. The arcuate nucleus is a primary site of satiety effect of leptin in rats. Neurosci. Lett. 224:149-152.

21. Elmquist, J.K., Maratos-Flier, E., Saper, C.B., and Flier, J.S. 1998. Unraveling the central nervous system pathway underlying responses to leptin. Nat. Neurosci. 1:445-450.

22. Seeley, R.J., et al. 1997. Melanocortin receptors in leptin effects. Nature. 
390-349.

23. Satoh, N., et al. 1998. Satiety effect and sympathetic activation of leptin are mediated by hypothalamic melanocortin system. Neurosci. Lett. 249:107-110.

24. Frederich, R.C., et al. 1995. Leptin levels reflect body lipid content in mice: Evidence for diet-induced resistance to leptin action. Nat. Med. 1:1311-1314.

25. Maffei, M., et al. 1995. Leptin levels in human and rodent: measurement of plasma leptin and ob RNA in obese and weight-reduced subjects. Nat. Med. 1:1155-1161.

26. Considine, R.V., et al. 1996. Serum immunoreactive-leptin concentrations in normal-weight and obese humans. N. Engl. J. Med. 334:292-295.

27. Agata, J., et al. 1997. High plasma immunoreactive leptin level in essential hypertension. Am. J. Hypertension. 10:1171-1174.

28. Ogawa, Y., et al. 1999. Increased glucose metabolism and insulin sensitivity in transgenic skinny mice overexpressing leptin. Diabetes. 48:1822-1829.

29. Masuzaki, H., et al. 1999. Glucose metabolism and insulin sensitivity in transgenic mice overexpressing leptin with lethal yellow agouti mutation: usefulness of leptin for the treatment of obesity-associated diabetes. Diabetes. 48:1615-1622.

30. Bultman, S.J., Michaud, E.J., and Woychik, R.P. 1992. Molecular characterization of the mouse agouti locus. Cell. 71:1195-1204.

31. Miller, M.W., et al. 1993. Cloning of the mouse agouti gene predicts a secreted protein ubiquitously expressed in mice carrying the lethal yellow mutation. Genes Dev. 7:454-467.

32. Halaas, J.L., et al. 1997. Physiological response to long-term peripheral and central leptin infusion in lean and obese mice. Proc. Natl. Acad. Sci. USA. 94:8878-8883.

33. Lu, D., et al. 1994. Agouti protein is an antagonist of the melanocytestimulating hormone receptor. Nature. 371:799-802.

34. Fan, W., Boston, B.A., Kesterson, R.A., Hruby, V.J., and Cone, R.D. 1997. Role of melanocortinergic neurons in feeding and the agouti obesity syndrome. Nature. 385:165-168.

35. Iwatsuka, H., Shino, A., and Suzuoki, Z. 1970. General survey of diabetic features of yellow KK mice. Endocrinol. Jpn. 17:23-35.

36. Kondo, K., Nozawa, K., Tomita, T., and Ezaki, K. 1957. Inbred strains resulting from Japanese mice. Bull. Exp. Anim. 6:107-116.

37. Ogawa, Y., et al. 1994. Molecular cloning of the complementary DNA and gene that encode mouse brain natriuretic peptide and generation of transgenic mice that overexpress the brain natriuretic peptide gene. $J$. Clin. Invest. 93:1911-1921.

38. Leigh, F.S.M., Kaufman, L.N., and Young, J.B. 1992. Diminished epinephrine excretion in genetically obese $(o b / o b)$ mice and monosodium glutamate-treated rats. Int. J. Obes. 16:597-604.

39. Shek, E.W., Brands, M.W., and Hall, J.E. 1998. Chronic leptin infusion increases arterial pressure. Hypertension. 31:409-414.

40. Casto, R.M., VanNess, J.M., and Overton, J.M. 1998. Effects of central leptin administration on blood pressure in normotensive rats. Neurosci. Lett. 246:29-32.

41. Lu, H., et al. 1998. Obesity due to high fat diet decreases the sympathet- ic nervous and cardiovascular responses to intracerebroventricular lepin in rats. Brain Res. Bull. 47:331-335.

42. Sierra-Honigmann, M.R., et al. 1998. Biological action of leptin as an angiogenic factor. Science. 281:1683-1686.

43. Bouloumie, A., Drexler, H.C.A., Lafontan, M., and Busse, R. 1998. Leptin, the product of ob gene, promotes angiogenesis. Circ. Res. 83:1059-1066.

44. Cao, G.Y., Considine, R.V., and Lynn, R.B. 1997. Leptin receptor in the adrenal medulla of the rat. Am. J. Physiol. 273:E448-E452.

45. Dunbar, J.C., and Lu, H. 1999. Leptin-induced increase in sympathetic nervous and cardiovascular tone is mediated by proopiomelanocortin (POMC) products. Brain Res. Bull. 50:215-221.

46. Haynes, W.G., Morgan, D.A., Djalali, A., Sivitz, W.I., and Mark, A.L. 1999. Interactions between the melanocortin system and leptin in control of sympathetic nerve traffic. Hypertension. 33:542-547.

47. VanNess, J.M., DeMaria, J.E., and Overton, J.M. 1999. Increased NPY activity in the PVN contributes to food-restriction induced reductions in blood pressure in aortic coarctation hypertensive rats. Brain Res. 821:263-269.

48. Morton, K.D.R, McCloskey, MJ.D, and Potter, E.K. 1999. Cardiorespiratory responses to intracerebroventricular injection of neuropeptide $\mathrm{Y}$ in anaesthetised dogs. Regul. Peptides. 81:81-88.

49. Stephens, T.W., et al. 1995. The role of neuripeptide Y in the antiobesity action of the obese gene product. Nature. 377:530-532.

50. Herberg, L., and Coleman, D.L. 1977. Laboratory animals exhibiting obesity and diabetes syndromes. Metabolism. 26:59-87.

51. Leibel, R.L., Chung, W.K., and Chua, S.C. 1997. The molecular genetics of rodent single gene obesities. J. Biol. Chem. 272:31937-31940.

52. Huszar, D., et al. 1997. Targeted disruption of the melanocortin-4 receptor results in obesity in mice. Cell. 88:131-141.

53. Segal, K.R., Landt, M., and Klein, S. 1996. Relationship between insulin sensitivity and plasma leptin concentrations in lean and obese men. Diabetes. 45:988-991.

54. Saladin, R., et al. 1995. Transient increase in obese gene expression after food intake or insulin administration. Nature. 377:527-529.

55. Ahima, R.S., et al. 1996. Role of leptin in the neuroendocrine response to fasting. Nature. 382:250-252.

56. Lord, G.M., et al. 1998. Leptin modulates the T-cell immune response and reverses starvation-induced immunosuppression. Nature. 394:897-901

57. Takaya, K., et al. 1996. Nonsense mutation of leptin receptor in the obese spontaneously hypertensive Koletsky rat. Nat. Genet. 14:130-131.

58. Phillips, M.S., et al. 1996. Leptin receptor missense mutation in the fatty Zucker rat. Nat. Genet. 13:18-19.

59. Kurtz, T.W., Morris, R.C., and Pershadsingh, H.A. 1989. The Zucker fatty rat as a genetic model of obesity and hypertension. Hypertension. 13:896-901.

60. Farooqi, I.S., et al. 1999. Effects of recombinant leptin therapy in a child with congenital leptin deficiency. N. Engl. J. Med. 341:879-884.

61. Heymsfield, S.B., et al. 1999. Recombinant leptin for weight loss in obese and lean adults: a randomized, controlled, dose-escalation trial. JAMA. 282:1568-1575 